\title{
VALOR PREDITIVO DA ULTRA-SONOGRAFIA DO CÉREBRO EM RECÉM-NATOS COM DIAGNÓSTICO DE MENINGITE BACTERIANA NEONATAL
}

\section{Seguimento de 12 anos}

\author{
Alexandra Maria Vieira Monteiro', Olga Bomfim²
}

\begin{abstract}
RESUMO - Objetivo: Avaliar o valor preditivo da ultra-sonografia do céreb ro, para o dano cerebral, em crianças com diagnóstico de meningite neonatal. Método: Estudo retrospectivo realizado no Instituto Fe rnandes Figueira (FIOCRUZ-RJ) em 16 crianças que realizaram ultra-sonografia do céreb ro por diagnóstico de meningite no período neonatal e tiveram seguimento neurológico até 12 anos. Foram calculados: valores p reditivos positivo e negativo, sensibilidade e especificidade. Resultados: $56,25 \%$ eram do sexo masculino e $81,25 \%$ prematuros. Hidrocefalia foi o achado mais freqüente $(56,25 \%)$, seguido pelo exame normal $(43,75 \%)$. Achados de hidrocefalia (9), somente em um havendo evolução favorável e achados normais (7), em $4(57,14 \%)$ não havendo déficit neurológico. Achados de ventriculite (4) e abscesso cerebral (2): todos evoluíram com dano cerebral. Diagnóstico de encefalomalácia (2); em 50\% havendo desenvolvimento cognitivo satisfatório. Diagnostico de atrofia (2), todos com dano cerebral severo. Conclusão: Valor preditivo positivo de $88,89 \%$, negativo de $57,14 \%$, sensibilidade de $72,73 \%$ e especificidade de $80 \%$.
\end{abstract}

PALAVRAS-CHAVE: ultra-sonografia, cérebro, meningite neonatal.

\section{P redictive value of cerebral ultrasound with respect to clinical outcome in infants diagnoses on neonatal meningitis: a focus 12 years later}

\begin{abstract}
Objective: To evaluate the predictive value of cerebral ultrasound in infants diagnoses on meningitis neonatal to the neurological outcome. Method: A re trospective study of 16 children admitted at Institute Fernandes Figueira RJ - Brazil, who had neonatal meningitis and were examined by cere bra I ultrasound. The neurologic outcome was evaluated until 12 years of age. Positive and negative predictive values, sensitivity and specificity were calculated. Results: $56.25 \%$ were male and $81.25 \%$ premature. $\mathrm{H}$ y d rocephalus was the most frequent finding (56.25\%) followed by normal exam (43.75\%). Findings of hydrocephalus (9) only one had good neurologic outcome; and normal exam (7): only $57.14 \%$ without brain damage. Findings of ventriculitis (4) and brain abscesses (2) all had neurologic damage. Diagnosis of encephalomalacia (2): only one had good cognitive function. Findings of cerebral atrophy (2) all with severe outcome. Conclusion: The positive and predictive values were: $88.89 \% ; 57.14 \%$ negative; sensitivity was $72.73 \%$ and specificity $80 \%$.
\end{abstract}

KEY WORDS: cerebral, ultrasound, neonatal meningitis.

A meningite bacteriana aguda neonatal continua a ser, notadamente em países ditos em desenvolvimento, um grave problema de mortalidade e de morbidade ${ }^{1-5}$. A ultra-sonografia do cére b roé o método de escolha no diagnóstico das afecções neste grupo etário, destacando-se a ausência de necessidade de sedação e a facilidade de realização do exame a beira do leito aquecido.

Além disso, considerando-se a possibilidade de rápida evolução do processo inflamatório no cérebro, a ultra-sonografia permite o acompanhamento diário e sem riscos para estes pequenos pacientes ${ }^{6}$. Vá-

\footnotetext{
Instituto Fernandes Figueiras, FIOCRUZ, Rio de Janeiro, Brasil*: 'Médica - Radiologista do Instituto Fernandes Figueira, FIOCRUZ, Professor Adjunto (Doutor em Medicina) dos Cursos de Graduação e de Pós-Graduação da Faculdade de Ciências Médicas da Universidade do Estado do Rio de Janeiro (UERJ); ${ }^{2}$ Médica do Departamento de Neonatologia do Instituto Fernandes Figueira, FIOCRUZ.
}

Recebido 6 Outubro 2005. Aceito 10 Fevereiro 2006

Dra. Alexandra Maria Vieira Monteiro - Rua Macedo Sobrinho 21/1 ${ }^{\circ}$ Andar - 22271-080 Rio de Janeiro RJ - Brasil. E-mail: monteiroamv@gmail.com 
rios estudos descritivos dos achados da ultra-sonografia na meningite neonatal têm sido re la ta $\mathrm{d} \mathrm{o}^{7-10}$, porém poucos com seguimento clínico ${ }^{7,11}$.

O objetivo deste estudo é avaliar o valor preditivo da ultra-sonografia do cérebro, para o dano cerebral, em crianças até 12 anos que tiveram o diagnóstico de meningite no período neonatal.

\section{MÉTODO}

Durante o período de 41 meses, de janeiro de 1989 a junho de 1993, foram assistidos 6360 recém-natos no Departamento de Neonatologia do Instituto Fernandes Figueira. Destes, 29 tiveram o diagnóstico de meningite neonatal. Treze recém-natos foram excluídos: 9 por óbito, 1 por associação com anomalia de desenvolvimento cerebral, 1 pelo diagnóstico de meningite por Cândida, 1 por diagnóstico de meningite por Herpes simples e outro por não ter sido possível o seguimento clínico. Dos 16 pacientes incluídos com diagnóstico de mening ite bacteriana, todos realizaram ultra-sonografia.

O aparelho de ultra-sonografia utilizado foi da marc a ALOKA modelo SSD-280LS com transdutor setorial de $5.0 \mathrm{MHz}$.

O protocolo de exame, através da fontanela anterior, incluiu cortes coronais e sagitais a época do diagnóstico e um segundo exame de controle de cura ou por importante piora clínica. A hidrocefalia, quando presente, foi graduada em leve, moderada ou severa. Pela complexidade da análise liquórica neste grupo etário os dados obtidos através de punção lombar foram analisados em conjunto com os dados clínicos e, nos casos duvidosos, foi repetido o exame do líquor para confirmação diagnóstica. A avaliação clínica neurológica foi realizada no primeiro ano de vida e agrupada por normal ou anormal. A avaliação clínica até 12 anos após o diagnóstico de meningite foi realizada por uma equipe multidisciplinar especializada e agrupada como desenvolvimento cognitivo (linguagem, fala e aprendizado escolar) e motor (distúrbios de tônus, equilíbrio e marcha).

\section{RESULTADOS}

Dos 16 pacientes 9 eram masculinos, 7 femininos, 13 prematuros e 3 a termo. Na correlação maturidade e peso 8 pre $m$ a t u ros tinham peso adequado à idade gestacional (AIG), 3 eram pequenos para a idade gestacional (PIG) e 2 grandes para a idade gestacional (GIG); dos recém-natos a termo 1 era PIG, 1 AIG e 1 GIG. Em relação à manifestação clínica da meningite, em 10 dos casos esta foi tardia. A sepse esteve presente em todos os casos. Dos aspectos clínicos neonatais, os sinais e sintomas de maior freqüência foram hipoatividade (15 casos), seguidos pela hiperte rmia (11 casos) e distúrbios respiratórios (10 casos). A convulsão esteve presente em 8 casos.

A punção lombar, com cultura do líquor, foi po-

Tabela 1. Aspectos clínicos e achados iniciais da ultra-sonografia (USG).

\begin{tabular}{ccllll}
\hline Caso & Sexo & Mat./Peso* & Manifestação & Agente etiológico & USG Inicial \\
\hline 1 & F & Prematuro/PIG & Precoce & Gram (-) Klebsiella sp & Hidrocefalia leve \\
2 & M & Prematuro/AIG & Precoce & Gram (-) & Ventriculite e abscesso \\
3 & M & Prematuro/AIG & Tardia & Gram (-) Proteus & Hidrocefalia leve \\
4 & F & Prematuro/GIG & Tardia & Gram (+) Esfilococos & Normal \\
5 & M & Termo/AIG & Tardia & Gram (-) & Normal \\
6 & F & Prematuro/GIG & Tardia & Gram (-) & Normal \\
7 & M & Prematuro/AIG & Precoce & Gram (-) Acinetobacter & Hidrocefalia leve e ventriculite \\
8 & F & Termo/PIG & Tardia & Gram (-) Klebsiella sp & Hidrocefalia severa \\
9 & F & Termo/GIG & Tardia & Indeterminado & Normal \\
10 & M & Prematuro/AIG & Precoce & Gram (+) Estreptococo B & Normal \\
11 & M & Prematuro/AIG & Tardia & Gram (-) E coli & Hidrocefalia moderada, ventriculite \\
12 & F & Prematuro/PIG & Tardia & Gram (-) Klebsiella & e abscesso, \\
13 & M & Prematuro/AIG & Precoce & Gram (-) & Normal \\
14 & M & Prematuro/PIG & Precoce & Indeterminado & Normal \\
16 & M & Prematuro/AIG & Tardia & Gram (-) Bacilo & Normal \\
\hline
\end{tabular}

\footnotetext{
* Relação maturidade/ peso
} 


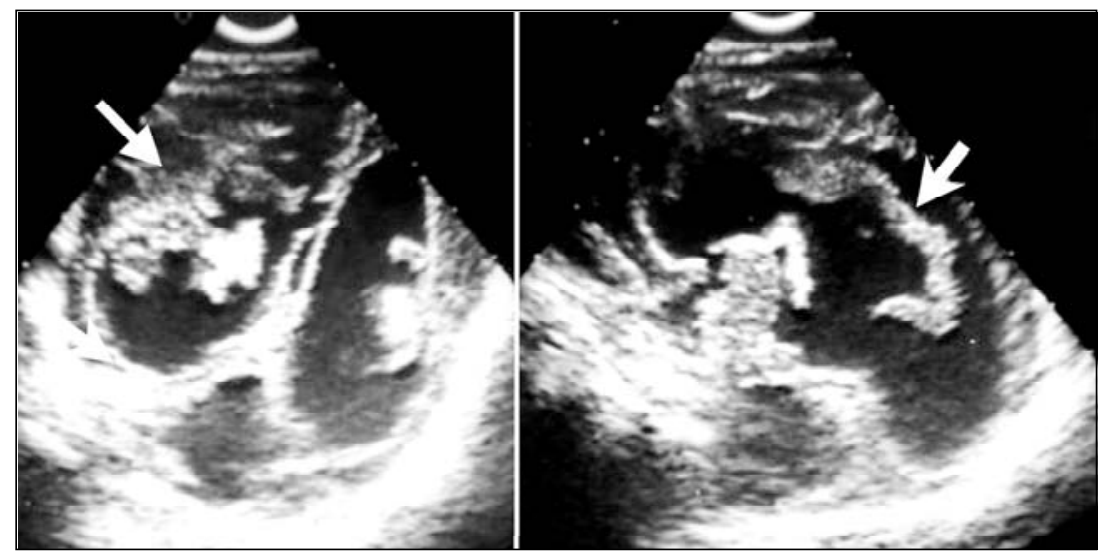

Fig 2. Cortes coronal ( $A$ ) e sagital (B) evi denciando dilatação ventricular com gru mos, ventriculite, e; coleção heterogênea no lobo frontal direito (setas) ocasionando compressão e desvio contralateral das es truturas da linha média. Abscesso cerebral.
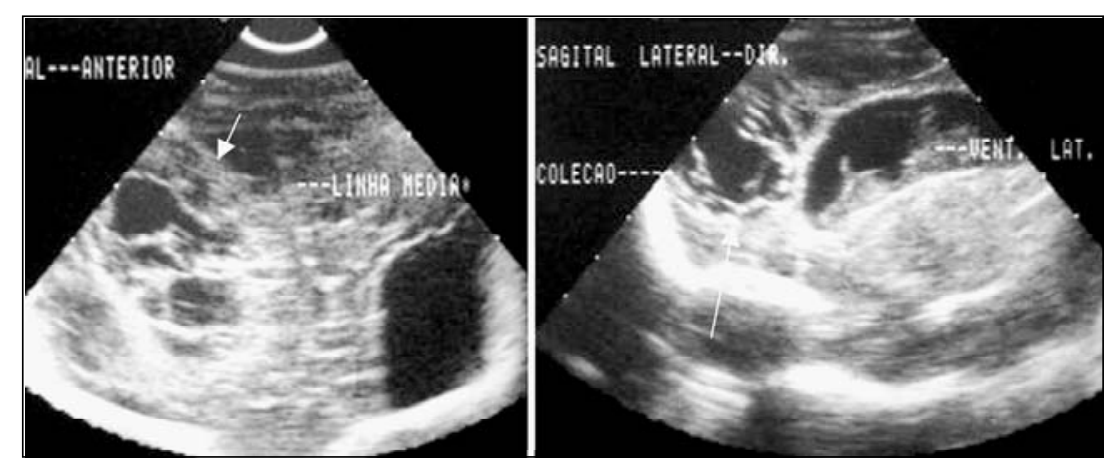

Fig 1. Cortes coronal (A) e sagital (B) evi denciando hidrocefalia tetra-ventricular contendo grumos piocitários de permeio (setas). Hidrocefalia e ventriculite.

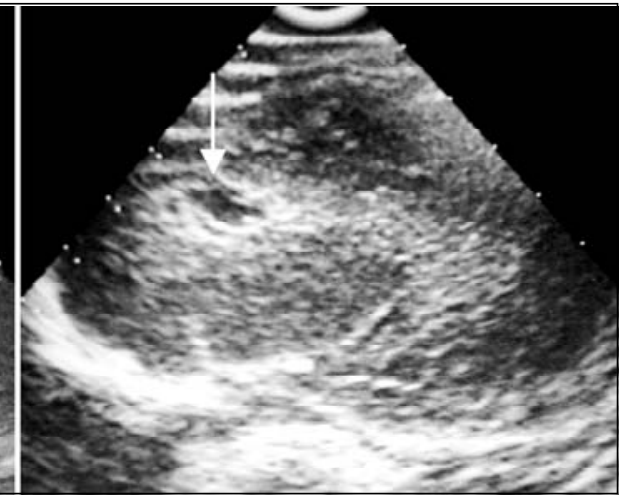

Fig 3. Cortes coronal ( $A$ ) e sagital (B) que mostram pequena área de leucomalácia periventricular frontal a direita(seta).
Fig 4. Corte coronal (A) e sagital (B) eviden ciando acentuação dos sulcos (seta cheia) e higroma subdural (seta tracejada) a es querda. Atrofia cortical cerebral. 
sitiva em 11 casos. A hipercelularidade foi diagnóstica em 5 casos $(23,81 \%)$. As bactérias Gram negativas foram mais freqüentes (11/16) do que as Gram positivas (3/16), e em 2 casos a bactéria foi indeterminada. Dos achados iniciais à ultra-sonografia o exame normal foi o mais encontrado (9/16), seguido pela hidrocefalia (5/16) e pela ventriculite (4/16)( Fig 1). Em nenhum dos casos de dilatação ventricular foi necessária a introdução de cateter de derivação. Houve dois casos de ventriculite com coexistência de abscesso ce rebral (Fig 2). O resumo dos achados clínicos e os achados da ultra-sonografia a época do diagnóstico estão listados na Tabela 1.

Dos achados finais, a hidrocefalia foi o mais freqüente (9/16) seguida pelo exame normal (7/16). Em dois casos identificamos encefalomalacia (Fig 3), inclusive em associação à atrofia (Fig 4).

Do total de 16 casos, $9(56,25 \%)$ apresentaram alterações na avaliação neurológica e 7 (43,75\%) apresentaram evolução neurológica normal até o primeiro ano de vida. Na avaliação neurológica até os 12 anos verificamos que dos 9 pacientes com alteração neurológica somente 1 (caso 3) apresentou bom desenvolvimento cognitivo e de aprendizado; todavia, com déficit motor. Dos 7 casos avaliados clinicamente como normais no primeiro ano de vida, somente 5 apresentaram bom desenvolvimento cognitivo e motor.

$\mathrm{Na}$ correlação entre os dados clínicos e os achados do último exame da ultra-sonografia verificamos que dos 7 casos diagnosticados como exame normal somente em 4 casos $(57,14 \%)$ a evolução neurológica foi normal nas duas avaliações neurológicas. Dos 9 casos de hidrocefalia, somente em 1, graduada como leve, houve evolução neurológica favorável nas duas avaliações. Dos 4 casos diagnosticados como ventriculite, todos apresentaram déficit neurológico variável. Dos 2 casos de encefalomalácia somente em 1 houve desenvolvimento cognitivo satisfatório. Dos pacientes diagnosticados como atrofia (2 casos) todos

Tabela 2. Correlação entre os achados do último exame da ultra-sonografia (UGS) e a evolução neurológica no primeiro ano e até o décimo-segundo ano de vida.

\begin{tabular}{|c|c|c|c|}
\hline Caso & USG final & $\begin{array}{l}\text { Evolução } \\
\text { até } 1 \text { ano }\end{array}$ & Evolução até o $12^{\circ}$ ano de vida \\
\hline 1 & Hidrocefalia leve & Normal & Bom desenvolvimento cognitivo e motor \\
\hline 2 & $\begin{array}{l}\text { Hidrocefalia moderada e } \\
\text { encefalomalacia }\end{array}$ & Anormal & $\begin{array}{l}\text { Bom desenvolvimento cognitivo e déficit } \\
\text { motor }\end{array}$ \\
\hline 3 & Hidrocefalia moderada & $\begin{array}{l}\text { Anormal } \\
\text { (ECNP) }\end{array}$ & ECNP \\
\hline 4 & Normal & Normal & Bom desenvolvimento cognitivo e motor \\
\hline 5 & Hidrocefalia moderada & Anormal & Déficit cognitivo e motor \\
\hline 6 & Normal & Anormal & Déficit cognitivo e motor \\
\hline 7 & Hidrocefalia moderada & Anormal & Déficit cognitivo e motor \\
\hline 8 & Hidrocefalia severa & Anormal & Déficit cognitivo e motor \\
\hline 9 & Hidrocefalia leve & Anormal & Déficit cognitivo e motor \\
\hline 10 & $\begin{array}{l}\text { Hidrocefalia leve e atrofia } \\
\text { cortical }\end{array}$ & Anormal & Déficit cognitivo e motor \\
\hline 11 & $\begin{array}{l}\text { Hidrocefalia moderada, atrofia } \\
\text { cortical e encefalomalacia }\end{array}$ & $\begin{array}{l}\text { Anormal } \\
\text { (ECNP) }\end{array}$ & ECNP \\
\hline 12 & Normal & Normal & Bom desenvolvimento cognitivo e motor \\
\hline 13 & Normal & Norrmal & Bom desenvolvimento cognitivo e motor \\
\hline 14 & Normal & Normal & Deficit cognitivo, bom desenvolvimento motor \\
\hline 15 & Normal & Normal & Bom desenvolvimento cognitivo e motor \\
\hline 16 & Normal & Normal & Déficit cognitivo e motor \\
\hline
\end{tabular}


a p resentaram dano cerebral. A correlação da ultrasonografia com a evolução neurológica Tabela 2.

O valor preditivo positivo calculado foi $88,89 \%$ (IC$83,21-94,57$ ) e o valor preditivo negativo, $57,14 \%$ (IC $49,78-64,51)$. A sensibilidade e a especificidade do método para o dano cerebral foram, respectivamente, de $72,73 \%$ (IC- $68,02-77,43$ ) e $80 \%$ (IC- $69.79-90,21$ ).

\section{DISCUSSÃO}

Os aspectos clínicos relacionados a mortalidade $\mathrm{e}^{1-13}$ e a morbidade ${ }^{13-15}$ conseqüentes a meningite já foram bem estabelecidos e estão em acordo aos nossos achados clínicos. Olmedo Diaz e cols. ${ }^{7}$ descreveram, em um estudo com 56 casos de meningite neonatal, dentreoutros fatores, a presença de ultra-sonografia alterada como fator de risco para seqüela neurológica, o que está plenamente em acordo aos nossos achados. Destacado por Snyder e col. ${ }^{16}$ a hidrocefalia, achado de ultra-sonografia final mais freqüente, esteve também associada ao déficit neurológico na maioria dos casos. Um aspecto interessante, descrito por Cabral e col. ${ }^{9}$, é o da evolução favorável de um paciente com diagnóstico final de hidrocefalia leve, tal qual o verificado nos nossos resultados. Descreveram estes que podem ocorrer dilatações ventriculares transitórias no curso da doença o que poderia, talvez, explicar esta evolução benigna.

Os achados descritivos da ultra-sonografia, como o exame ultra-sonográfico normal na vigência de meningite, foi também descrito por outros autore $s^{8}$. $\mathrm{Na}$ correlação clínico-neurológica verificamos, entretanto, uma evolução desfavorável em alguns pacientes. Estes achados devem-se, provavelmente, a lesões destrutivas na substância branca que não foram identificadas à ultra-sonografia.

A detecção da ventriculite implica em infecção grave no sistema nervoso central (SNC), geralmente associada a pior prognóstico ${ }^{17}$, e é melhor identificada à ultra-sonografia do que à tomografia computadorizada ${ }^{10}$. No nosso estudo todos os pacientes diagnosticados com ventriculite apresentaram déficit motor e, somente em um caso, o desenvolvimento cognitivo foi satisfatório. Neste grupo, dois recém-natos apre- sentaram associação com abscesso cerebral. Estudo so b re infecções no $\mathrm{SNC}^{6}$ descreve que a presença de alterações no parênquima está associada com severas alterações neurológicas, notadamente na coexistência de abscessos, infreqüentes no período neonatal ${ }^{10}$.

Dos achados finais de encefalomalácia e atrofia cortical, todos os pacientes tiveram elevada morbidade, o que está literalmente em acordo a outros autores ${ }^{10}$. A ultra-sonografia do cére b ro é, portanto, capaz de adicionar, na avaliação clínica preditiva do dano cerebral, em recém-natos, com diagnóstico de meningite.

\section{REFERÊNCIAS}

1. A i rede AI. Neonatal bacterial meningitis in the middle belt of Nigeria. Develop Med Child Neurol 1993;35:424-430.

2. Mo renoMT, Va rgas S, Poveda R, Saez-Llorens X. Neonatal sepsis and meningitis in a developing Latin American country. Pediatr Infect Dis J 1994;13:516-520.

3. Ramos SR, Feferbaum R, Manissadjian A, Vaz FA. Neonatal bacterial meningitis: etiological agents in 109 cases during a 10 year period. Arq Neuropsiquiatr 1992;50:289-294.

4. Heath PT, Nik Yusoff NK, Baker CJ Neonatal meningitis. Arch Dis Child Fetal Neonatal 2003;88:F173-F178.

5. Stevens JP, Eames M, Kent A, Halket S, Holt D, Harvey D. Long term outcome of neonatal meningitis Arch Dis Child Fetal Neonatal 2003;88:F179-F184.

6. Fitz CR. Inflamatory diseases of the brain in childhood. Am J Neuroradiol 1992:551-567.

7. Olmedo Diaz I, Pallas Alonso CR, Miralles Molina M, Simon de las Heras R, Rodrigues Otero J, Chasco Irigoyen A. Neonatal meningitis: study of 56 cases. An Esp Pediatr 1997;46:189-194.

8. Han BK, Babcock DS, McAdams L. Bacterial meningitis in infants: sonographic findings. Radiology 1985;154:645-650.

9. Cabral DA, Flodmark O, Farrell K, Speert DP . Prospective study of CT in acute bacterial meningitis. J Pediatr 1987;111:201-205.

10. Frank JL. Sonography of intracranial infection in infants and children. Neuroradiology 1986;28:440-451.

11. Anderson V, Anderson P, Grimwood K, Nolan T. Cognitive and executive function 12 years after childhood bacterial meningitis: effect of acute neurologic complications and age of onset. J Pediatr Psychol 2004;29:67-81.

12. Holt DE, Halket S, de Louvois J, et al. Neonatal meningitis in England and Wales: 10 years on. Arch Dis Child Fetal Neonatal 2001;84:F85-F89.

13. Bedford $\mathrm{H}$, de Louvois J, Halket $\mathrm{S}$, et al. Meningitis in infancy in England and Wales: follow up at age 5 years. BMJ 2001;323:533-536.

14. Klinger G, Chin CN, Beyene J, Perlman M. Predicting the outcome of neonatal bacterial meningitis. Pediatrics 2000;106:477-482

15. Jornada Krebs VL, Albuquerque Diniz EM, Costa Vaz FA, Marques Dias MJ, Takiguti C, Araujo Ramos JL. Neonatal bacterial meningitis: p rospective study of the long-term outcome of 55 children. A rq Neuropsiquiatr 1996;54:75-81.

16. Snyder RD. Ventriculomegaly in childhood bacterial meningitis. Neuropediatrics 1984;15:136.

17. Carey BM, Arthur RJ, Houlsby WT. Ventriculitis in congenital rubella: ultrasound demonstration. Pediatr Radiol 1987;17:415-416. 